\title{
Interaction between the dietary indices (DQI, DPI, HEI) and PPAR- $\gamma$ gene variants on cardiovascular risk factors in a patient with type 2 diabetes mellitus
}

\author{
Faezeh Abaj ${ }^{1}$, Gity Sotoudeh ${ }^{1}$, Elmira Karimi ${ }^{1}$, Masoumeh Rafiee ${ }^{1}$, and Fariba Koohdani ${ }^{1}$ \\ ${ }^{1}$ Tehran University of Medical Sciences
}

November 30, 2020

\begin{abstract}
Background: We investigated the interaction between PPAR- $\gamma$ Pro12Ala polymorphism and Healthy Eating Index (HEI), Dietary Quality Index-International (DQI-I) and Dietary Phytochemical Index (DPI) on Cardiovascular Disease (CVD) risk factors in patients with type 2 diabetes mellitus (T2DM). Methods: This cross-sectional study was conducted on 393 diabetic patients. PPAR- $\gamma$ Pro12Ala was genotyped by PCR-RFLP method. Biochemical markers including total cholesterol (TC), lowdensity lipoprotein (LDL), high-density lipoprotein (HDL), triglyceride (TG), superoxide dismutase (SOD), C-reactive protein (CRP), total antioxidant capacity (TAC), pentraxin-3 (PTX3), isoprostaneF2 $\alpha$ (PGF2 $\alpha$ ) were measured by standard protocol. FFQ was used for dietary indices (DQI, DPI, HEI) calculation. Results: There was no significant relationship between PPAR- $\gamma$ Pro12Ala polymorphism and CVD risk factors. The rs1801282-DQI interactions were significant on WC $(\mathrm{P}=0.01)$. Thus, C-allele carriers in the higher tertile of DQI had higher WC compared to GG homozygous. Further, an interaction was observed between PPAR rs1801282 polymorphism and DQI on serum IL-18 level $(\mathrm{P}=0.03)$. Besides, a significant rs1801282-DPI interaction was shown on HDL concentration (P Interaction=0.04), G allele carriers who were in the highest tertile of DPI, had lower HDL. Moreover, there were significant rs1801282-HEI interactions on ghrelin $(\mathrm{P}=0.04)$ in the crude model and serum leptin $(\mathrm{P}=0.02)$ in the adjusted model. Individuals with $(\mathrm{CC}, \mathrm{CG})$ genotypes in the higher tertile of HEI, had lower leptin and ghrelin concentration. Conclusions: Higher dietary indices (DQI, DPI, HEI) may affect the relationship between PPAR- $\gamma$ Pro12Ala polymorphism and waist circumference and ghrelin, leptin, HDL-c, IL-18 concentration in patients with T2DM. To date, studies on this polymorphism have been shown that this gene can interact with diabetes and different nutritional factors. For the first time, this study provides information on the interaction of dietary indices (DQI, DPI, HEI) and PPAR- $\gamma$ gene which is functionally effective in nutrient metabolism.
\end{abstract}

\section{Hosted file}

Manuscript.pdf available at https://authorea.com/users/380085/articles/496203-interactionbetween-the-dietary-indices-dqi-dpi-hei-and-ppar-\%CE\%B3-gene-variants-on-cardiovascularrisk-factors-in-a-patient-with-type-2-diabetes-mellitus

\section{Hosted file}

Figures.pdf available at https://authorea.com/users/380085/articles/496203-interactionbetween-the-dietary-indices-dqi-dpi-hei-and-ppar-\%CE\%B3-gene-variants-on-cardiovascularrisk-factors-in-a-patient-with-type-2-diabetes-mellitus

\section{Hosted file}

Tables.pdf available at https://authorea.com/users/380085/articles/496203-interactionbetween-the-dietary-indices-dqi-dpi-hei-and-ppar-\%CE\%B3-gene-variants-on-cardiovascularrisk-factors-in-a-patient-with-type-2-diabetes-mellitus 